\title{
Multicriteria optimization of oil and gas enterprises financial stability using the genetic algorithm method
}

\author{
Marta Shkvaryliuk ${ }^{1, *}$, Liliana Horal $^{1, * *}$, Inesa Khvostina $^{1, * * *}$, Natalia Yashcheritsyna $^{1, * * * *}$, and Vira Shiyko ${ }^{1, \dagger}$ \\ ${ }^{1}$ Ivano-Frankivsk National Technical University of Oil and Gas, 15 Karpatska Str., Ivano-Frankivsk, 76019, Ukraine
}

\begin{abstract}
The article considers the problem of optimizing the financial condition of oil and gas companies. The offered methods of optimization of a financial condition by scientists from different countries are investigated. It is determined that the financial condition of the enterprise depends on the effectiveness of the risk management system of enterprises. It is proved that the enterprises of the oil and gas complex need to develop a system for risk management to ensure the appropriate financial condition. The financial condition is estimated according to the system of certain financial indicators, the integrated indicator of financial condition assessment is constructed using the method of taxonomy. According to the results of the calculation of the integrated indicator, it is concluded that this indicator does not have a stable trend. On the basis of the conducted researches it is offered to carry out optimization of an integral indicator of a financial condition with use of genetic algorithm in the Matlab environment. Based on the obtained results, recommendations of the management of the researched enterprises on increase of management efficiency are given.
\end{abstract}

\section{Introduction}

The loss of financial stability of any enterprise in a turbulent environment, which is exacerbated by negative external factors is a reality today. This fact leads to many negative consequences, one of which is bankruptcy and liquidation of the enterprise. Due to the fact that the reduction of financial stability of enterprises that provide Ukraine's economic and energy security has become a reality, there is an urgent need to optimize their financial stability. Examining various scientific sources related to the solution of this problem, we can conclude that there are many ways to optimize financial stability. However, we propose to use the genetic algorithm method in the process of the studied enterprises financial stability optimizing, which by optimizing the financial stability will generate optimal values of the enterprise internal factors. Which in the future will allow the company's management to make optimal management decisions and reduce the risk of its loss..

\section{Background}

Important contribution to the study of financial sustainability was made authors of [1-3].

The authors of [1] propose an economic and mathematical model of the assessing financial stability process by calculating the integral indicator of the service sector financial stability. To study the stability and controllability of the assessing financial stability process, the types of

\footnotetext{
*e-mail: marta.shkvaryliuk@gmail.com

**e-mail: liliana.goral@gmail.com

***e-mail: inesa.hvostina@gmail.com

****e-mail: yashcheritsyna@gmail.com

†e-mail: vnkShiyko@gmail.com
}

control maps for each of the coefficients were determined. Proposed apparatus of neural networks makes it possible not only to determine the most profitable activity of an enterprise but also to assess the financial condition of each of its research objects.

The main results of the G. Azarenkova, O. Golovko and K. Abrosimova study [2] are following: the theoretical and essential characteristics of enterprise financial sustainability has been determined; the financial status of PJSC "Turboatom" has been analyzed; the taxonomic index of financial sustainability has been calculated and the forecast of its significance has been made, the approaches to increase enterprise financial sustainability have been proposed.

The article [4] provides practical advice for enterprises to achieve the highest possible level of energy and financial security.

In work [3] an eigenstate method is proposed to analyse the basic indicators of the enterprise as it allows to construct an economical stability model of such enterprise, describe the methodology for analyzing the economic stability of an enterprise on the basis of eigenstate method, provides formulas for calculating the complex indicator of economic stability. The efficiency of the methodology is demonstrated with evidence from the economic stability analysis of the trading company.

W. Ma, M. Jin, Y. Liu and X. Xu in [5] analyze the relationship between enterprise management and financial performance, analyze the mean and heterogeneity of the enterprise management team characteristics, mathematically models its relationship, constructs fractional differential equations, and tests it through empirical research. The influence of the enterprise management age character- 
istics, international experience, education level, team size and government background on the financial performance of the company.

A positive aspect of modern research on solving the problem of optimizing financial stability is also the fact that in many works the problem is proposed to be solved by building an effective system of risk management in enterprises. In particular, this issue is considered in the [1, 69].

Research results of D. M. Sprčić, A. Kožul and E. Pecina [6] have revealed low levels of ERM development in listed Croatian companies. Managers are focused on financial and operative risk management, while strategic and other risks have been neglected. Regression analysis has indicated somewhat unexpected but important conclusion - the explored risk management rationales have weak predictive power in explaining corporate risk management decisions in Croatian companies. The level or risk management system development is dependent only on the size of the company and value of the growth options [6].

J. Cohen, G. Krishnamoorthy and A. Wright in [7] distinguish three major findings from our study. First, importantly, all three types of participants see a strong link between ERM and the financial reporting process. Second, despite recognition of the broad nature of ERM, the predominant experiences of the actual roles played by triad members center on agency theory, while resource dependence may be relatively underemphasized by all triad members. Finally, CFOs and AC members indicate that auditors may be especially underutilizing ERM in the audit process, suggesting an "expectations gap" [7].

The paper [10] proposes an approach to modeling the business climate of the country, which is based on the financial and economic indicators, and makes it possible to assess the development trends of the studied indicator. The proposed approach is based on the taxonomy method.

The analysis of sustainability and security of enterprises was carried out using a wide range of classical and advanced modeling methods, in particular, in article [11].

In our previous studies [12] it was possible to achieve an increase in the efficiency of modeling financial risk through the formation of an ensemble of models.

In article [13] is demonstrated the possibility of studying complex socio-economic systems as part of a network paradigm of complexity.

After conducting research on scientific papers that solve the problem of the economic entities financial stability loss risk reduction, it can be concluded that the optimization of financial condition through the use of a genetic algorithm has not been carried out. Therefore, this issue is relevant and needs research.

The analysis of methodological approaches to assessing the financial stability of economic entities shows the lack of a single methodological basis for assessment. Moreover, differences are manifested both in the components of financial stability, the system of indicators, and in the method of their consideration in the analysis of financial stability. All this necessitates the development of fundamentally new approaches and tools for assessing the financial stability of enterprises.

\section{Methodology}

Consider the dynamics of average indicators of liquidity, solvency, profitability and business activity of Ukraine's oil and gas industry, table 1 .

Table 1. Dynamics of financial indicators' average values of Ukrainian oil and gas industry

\begin{tabular}{llllll}
\hline \multirow{2}{*}{ Indicators } & \multicolumn{5}{c}{ Years } \\
\cline { 2 - 6 } & 2015 & 2016 & 2017 & 2018 & 2019 \\
\hline Current Ratio & 89,6 & 93,3 & 98,7 & 103 & 84,7 \\
Equity-to-assets & 18,1 & 16,9 & 18,4 & 3 & 1 \\
ROA & $-0,1$ & 0,1 & 0,8 & 3,4 & 1,6 \\
WCP & $-0,1$ & 0,1 & 1,5 & 6,9 & 3,8 \\
CashRatio & 1 & 1 & 1,9 & 1,3 & 1 \\
NPM & 0 & 0,3 & 1,8 & 4,5 & 4,4 \\
ROTA & 0 & 0,5 & 1,4 & 4,7 & 3,1 \\
Tot. Ass Turn. & 0,8 & 0,7 & 0,8 & 1 & 0,7 \\
Rec. Turn. & 3,4 & 2,9 & 4,1 & 4,5 & 3,5 \\
\hline
\end{tabular}

Table 2. Growth rates (basic) of financial indicators' average values of Ukrainian oil and gas industry, \%

\begin{tabular}{llllll}
\hline \multirow{2}{*}{ Indicators } & \multicolumn{5}{c}{ Years } \\
\cline { 2 - 6 } & 2015 & 2016 & 2017 & 2018 & 2019 \\
\hline Current Ratio & 1,00 & 1,04 & 1,10 & 1,15 & 0,94 \\
Equity-to-assets & 1,00 & 0,93 & 0,10 & 1,86 & 1,67 \\
ROA & 1,00 & 1,00 & 8,00 & 34,00 & 16,00 \\
WCP & 1,00 & 1,00 & 15,00 & 69,00 & 38,00 \\
CashRatio & 1,00 & 1,00 & 1,90 & 1,30 & 1,00 \\
NPM & 1,00 & 1,00 & 6,00 & 15,00 & 14,67 \\
ROTA & 1,00 & 1,00 & 2,80 & 9,40 & 6,20 \\
Tot. As. Turn. & 1,00 & 0,88 & 1,00 & 1,25 & 0,88 \\
Rec. Turn & 1,00 & 0,85 & 1,21 & 1,32 & 1,03 \\
\hline
\end{tabular}

According to table 1, it was established that the current ratio does not exceed the regulatory value of $100 \%$ in contrast to 2018 , where the value of the indicator is $103.0 \%$. Current ratio characterizes the ability of enterprises to repay their current liabilities for up to 1 year through current assets. The liquidity indicator shows that the analyzed enterprises do not have enough resources that can be used to repay short-term creditors' claims, the change in the studied indicator ranges from $84.7 \%$ to $98.7 \%$. In 2018 , the overall increase over four years increased by $14.96 \%$ and in 2019 there is a decrease of $5.47 \%$ compared to the base value.

The value of the Cash ratio did not reach the normative value of $20 \%$. During 2015-2019 the value of the indicator ranges from $1.0 \%$ to $1.9 \%$, i.e., money and their equivalents are not enough to meet the current liabilities of economic entities. The Equity-to-Assets - the solvency indicator characterizes the share of equity of enterprises in the total amount of funds invested in its activities. The value of the Equity-to-Assets does not exceed the normative by $50 \%$ and fluctuates during the study period in the 
range of $16.9-33.8 \%$, so there is every reason to believe that enterprises are not solvent.

According to table 2, return on assets (ROA) determines the return of 1 hryvnia assets of economic entities, its value increases rapidly from $0.1 \%$ in 2016 to $3.4 \%$ in 2018 , then decreases to $1.6 \%$. The dynamics of working capital profitability is similar, the value of the indicator increases from $0.1 \%$ in 2016 to $6.9 \%$ in 2018 , decreases to $3.8 \%$ in 2019 . The profitability indicator is the net margin (NPM), which reflects the ratio of net profit to the total revenue of the enterprise whose value increased from $0.3 \%$ in 2016 to $4.5 \%$ in 2018 and decreased to $4.4 \%$ in 2019 . The ratio of operating profit to assets of oil and gas companies (ROTA) characterizes the return on total assets, the value which also increased from $0.5 \%$ in 2016 to $4.7 \%$ in 2018 and decreased to $3.1 \%$ in 2019.

The state of business activity in the context allows you to determine the productivity of assets of enterprises. The value of the indicator in the industry ranges from $0.7-1$ for the study period. Working capital turnover - an indicator of business activity, which shows the efficiency of enterprises working capital usage in terms of revenue generated by them. According to the values of the indicator, the efficiency of its generation for the period under study is 0 . The turnover of receivables shows how many times during the year receivables are repaid. The ability of entities to repay receivables during the period under review changes abruptly. The highest value is observed in 2018 and is 4.5 and the lowest value is 2.9 in 2016, due to the crisis of payments in the country.

Given the results of the calculated average values of Ukraine's oil and gas industry financial indicators and their dynamics, it is possible to draw conclusions about the instability of their trends, which necessitates the calculation and modeling of an integrated indicator of financial condition. The taxonomy method was used for its construction, the results of its calculation and forecasting are shown in figure 1.

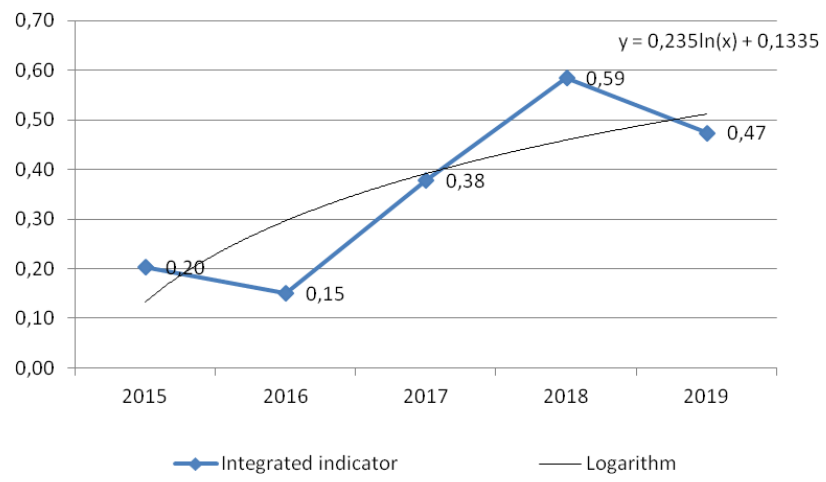

Figure 1. Dynamics of the integrated indicator of Ukrainian oil and gas enterprises' financial condition

According to figure 1, it is determined that the value of the integrated indicator of Ukraine's oil and gas companies financial condition increases from 2016 to 2018, then decreases to 0.47 in 2019 . The decrease in the integrated indicator shows a certain signaling ability to reduce financial stability of oil and gas companies increase in the general level of financial risks.

Variation of indicators acquires a difference due to a significant difference between the maximum and minimum values of the sample. It can be noted that the taxonomy index in the industry was unstable during the analyzed periods: the closer this indicator is to 1 , the lower the level of risk. As you can see, the level of risk of the financial condition is quite high for the analyzed period. According to the results of the forecast, the negative trend of the taxonomic indicator can be stated, so if we do not change the conditions of operation and development of oil and gas companies in the future, negative trends will further worsen the financial condition of companies in Ukraine's oil and gas industry. There is a need to develop effective management solutions to provide enterprises with a vector of positive development, this problem is of national importance and needs proper attention.

To begin with, it is necessary to find the optimal values of input parameters that form a stable financial condition of the enterprise, provide a sufficient level of the studied industry financial condition integrated indicator at a level above average, 0.6-1.0. Thus, we have the first restrictions on the function of the financial condition integrated indicator.

The problem of optimization problems has been in the field of view of domestic economics representatives for a long time. To determine the extreme values classical methods of higher mathematics are widely used, consider one of the most interesting and modern options - genetic algorithms. The most popular from a scientific point of view is, the use of an algorithm for finding optimization solutions using mathematical modulation of genetic processes. In his works, he shows the possibilities and patterns of heredity and variability in genetics in the transfer to the problem of determining the optimization values. Ideas and methods of genetics play an important role in genetic engineering and are applied to economic problems. The mechanism of heredity means the role of genes as elementary carriers of hereditary information. Scientists showed the work of the so-called "genetic" operators of ascent, mutation, mathematical implementation of single-point and multi-point crossover, the search for the most adapted individual.

In mathematics, the problem of stability arises when a physical object is perturbed in phase space, that is, when external forces take it out of equilibrium. As a result, the object can: move away from equilibrium; be in a slight deviation from it; return to equilibrium, withstanding adverse fluctuations.

In fact, the behavior of an object in an disturbed state determines the stability or instability of its undisturbed equilibrium state. Thus, the equilibrium state of an object can be considered stable when, after perturbation, it enters a state close to equilibrium or when it returns to it.

To study the phenomenon of stability in more detail, it is necessary to use the concept of "area of stability". It is often necessary to determine the effect of changing certain parameters on stability. To do this, build the stability area of the object in the space of changing parameters. The area of stability is determined by the set of values of the param- 
eters of the object for which it is stable. Going beyond the parameter limit limits the object from steady to unstable. When the limit of stability is exceeded, the level of risk increases significantly. It is clear that the transition from the zone of stability to the unstable position is determined not by the boundary line, but by some area that can be called transitional.

Drawing analogies between economic and mechanical equilibrium, we should pay attention to the differences between static and dynamic equilibria. At static equilibrium the motion of an object ceases, whereas at dynamic equilibrium the physical body continues to move, but at the same time certain total characteristics of the system remain unchanged. An example is the flow of water in the riverbed: the height of the water and the speed of the flow can be constant, and its parameters, such as inflow and outflow, can change. In other words, static equilibrium implies the ability of the system in it, after minor deviations to return to the previous state, and dynamic equilibrium can be interpreted as the ability of a mechanical system in motion under the influence of certain forces, not to deviate from a given trajectory at insignificant accidental stresses or deviations.

Speaking of the enterprise financial stability, it is advisable to draw analogies with the dynamic stability, because the functioning of the oil and gas sector, its functions, the implementation of the whole complex of active and passive operations is nothing but a dynamic process. Thus, the financial stability of enterprises - one of the key dynamic characteristics of its activities, which largely reveals its viability. In the future, we will consider that the financial stability of the enterprise is a dynamic category, which is the ability to return to equilibrium after leaving it as a result of a certain impact. Sustainability in economic systems, despite some similarities with technical ones, is a much more complex concept. In view of this, analogies can be made for economic systems only conditionally. Due to the fact that a universal approach to assessing financial stability as a single scalar indicator has not yet been developed, we propose to use the tools of multi-criteria optimization, which can be used to implement the concept of economic equilibrium.

We believe that a financially stable enterprise must achieve a certain equilibrium - the optimal ratio between risk, return, liquidity and other key financial performance indicators, on which depends its financial stability. As target functions we will take the key financial indicators of the oil and gas company: current liquidity, autonomy ratio, net margin and receivables turnover, which according to the correlation-regression analysis have the greatest impact on the integrated indicator of financial stability. To achieve a certain equilibrium of the bank should optimize all these criteria, taking into account its real financial condition. In addition, the task of constructing Paretoeffective financial indicators that optimize the integrated indicator of financial stability is proposed.

To find solutions to the multicriteria optimization problem, we use the method of genetic algorithm, which has proven itself well for solving this class of problems. A genetic algorithm is a heuristic search algorithm that is applied to optimization and modeling problems by random selection based on the use of mechanisms resembling evolutionary processes in nature. They are a kind of evolutionary methods of calculation. Genetic algorithm - a method of optimization based on the concepts of natural selection and genetics. In this approach, the variables that characterize the solution are represented as genes on the chromosome. The genetic algorithm, operating on a finite number of solutions (population), generates new solutions in the form of various combinations of parts of the solutions of this population. Operators such as selection, recombination and mutation are used for this purpose.

In a genetic algorithm, a chromosome is a numerical vector that corresponds to a variable. Each of the chromosome vector positions is called a gene.

The genetic algorithm is actually a kind of random search and is based on approaches that resemble the mechanism of natural selection. In a genetic algorithm, some random set of initial data, called a population, is first formed. Each element of the population is called a chromosome and represents some solution of the problem in the first approximation, i.e. satisfies the system of constraints of the problem. Chromosomes evolve during iterations called generations (or generations). During each iteration, the chromosome is evaluated using some degree of compliance (fitness function), which is also called compliance function. A mutation is an operation that implements random changes in different chromosomes.

The simplest mutation is to randomly alter one or more genes. In a genetic algorithm, a mutation plays an important role in restoring genes dropped from a population during a selection operation so that they can be used in new populations. In addition, it allows the formation of genes that were not present in the original population. The intensity of mutations is determined by the mutation rate, which is the proportion of genes that are mutated in this iteration. Too small a value of this factor means that many genes that could be useful will never be considered. At the same time, too large a value of the coefficient will lead to large random perturbations. Descendants will no longer be like their parents and the algorithm will lose the ability to learn while maintaining hereditary traits.

We used the Matlab Optimization Toolbox to find Pareto-effective sets of unit coefficients. The standard adaptive feasible mutation function was chosen as the mutation operator, which is used for constrained tasks and allows you to randomly generate directions based on the most recent successful or unsuccessful generations. To perform the crossover operation, the Scattered method was used, which involves creating a random binary vector and selecting genes from the first parent chromosome for which the corresponding value is 1 , or from the second parent chromosome when the value is 0 when combining these genes to form a new offspring.

A multicriteria problem is often understood not as a verbal description of the problem, but as its model, namely: a multicriteria problem is a mathematical model of making an optimal decision based on several criteria. These criteria may reflect assessments of the different qualities of the object or process about which the decision 
is made. Formally, the multicriteria problem as a model is given in the form:

$$
F(x) \rightarrow \text { max for all } x \in \mathbb{D},
$$

where $\mathbb{D}$ is the set of valid solutions; $F(x)$ is a vector function of the argument $x$ (integral indicator of financial condition), which can be represented as follows:

$$
F(x)=\left[f_{1}(x), f_{1}(x) \ldots, f_{k}\right],
$$

where $f_{1}(x), f_{2}(x) \ldots f_{k}(x)$ - scalar functions of the vector argument $\mathrm{x}$ each of which is a mathematical expression of one optimaliti criterion.

Since this model uses a vector objective function, it is often called the problem of vector optimization. Obviously, problem (1) does not belong to the class of mathematical programming problems, because the models of this class of problems always contain only one objective function of the vector argument.

Here we consider a complex vector criterion, which can be used to achieve the maximum effect, without necessarily reaching the extreme in all functions. The existence of a solution that literally maximizes all target functions is a rare exception. The problem of vector optimization in the general case does not have a clear mathematical solution. To obtain a solution, it is necessary to use additional subjective information of a specialist in this subject area, which is commonly referred to as a decision maker. This means that when solving the problem by different specialists with the involvement of different sources of information, most likely different answers will be received. Problems of vector optimization are currently considered in the framework of decision theory [10], the main feature of which is the presence of uncertainty. This uncertainty cannot be ruled out by various modeling techniques and objective calculations. In multicriteria problems, the uncertainty is that it is not known which criterion to prefer and to what extent. To eliminate this uncertainty, it is necessary, firstly: to formulate a special principle of optimality, and secondly: to involve additional subjective information of the decision-maker based on his experience and intuition.

Therefore, in accordance with the above information, we formulate the objective functions and conditions of optimization. The function $G(x)$ is defined as an integrated indicator of financial condition calculated by the taxonomy method and takes into account the levels of unit indicators that were previously selected to be included in the integrated indicator of financial condition $Y(x)$ :

$$
\begin{aligned}
Y(x) & =-0,17432-0,00076 x_{1}+0,00095 x_{2}+ \\
& +0,055039 x_{3}+0,125108 x_{4}
\end{aligned}
$$

and Finscore $(G(x))$ :

$$
\begin{aligned}
G(x) & =3,639721+0,009527 x_{1}-0,03471 x_{2}+ \\
& +0,13336 x_{3}-0,16618 x_{4} .
\end{aligned}
$$

Therefore, taking into account the constructed relationship between the studied enterprise financial condition
$Y(x)$ and Finscore $G(x)$ integrated indicator and its unit indicators, it is necessary to optimize the complex indicator of financial condition, maximize it by optimizing independent variables.

First, let's set the problem by describing the stages of optimization. Figure 2 shows the stages of the optimization process.

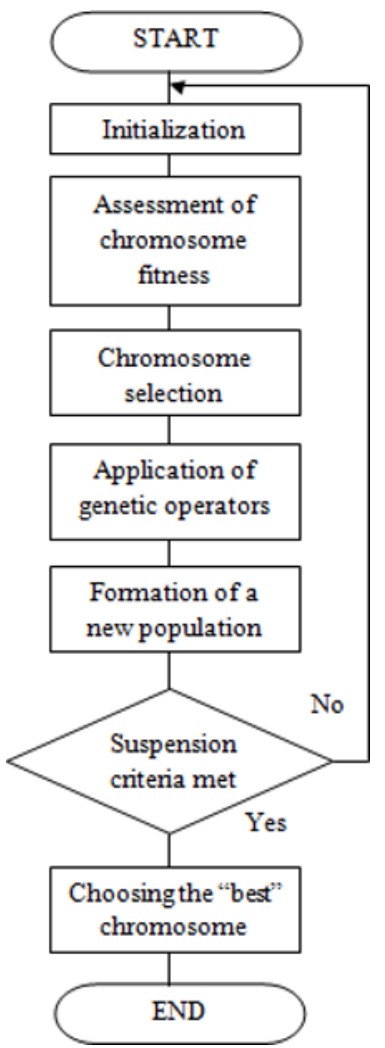

Figure 2. Conditional block diagram of the genetic algorithm

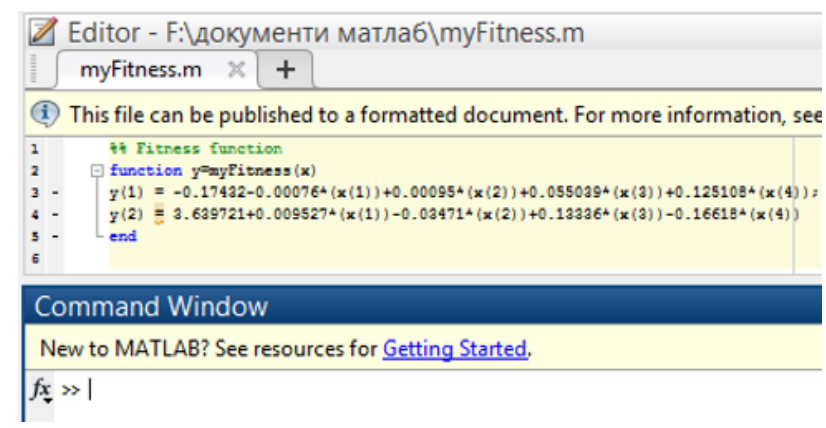

Figure 3. M-file in Matlab

Therefore, we need to optimize, namely to maximize the financial condition, it should be as close as possible to 1 , but there are some limitations, which will be described below. Next, we will implement the financial condition integrated indicator function optimization in MatLab with pre-imposed restrictions on independent variables. First, we form an $\mathrm{m}$-file in which we introduce the optimized function, in the economic-mathematical model of the integrated indicator of the financial condition of the object 


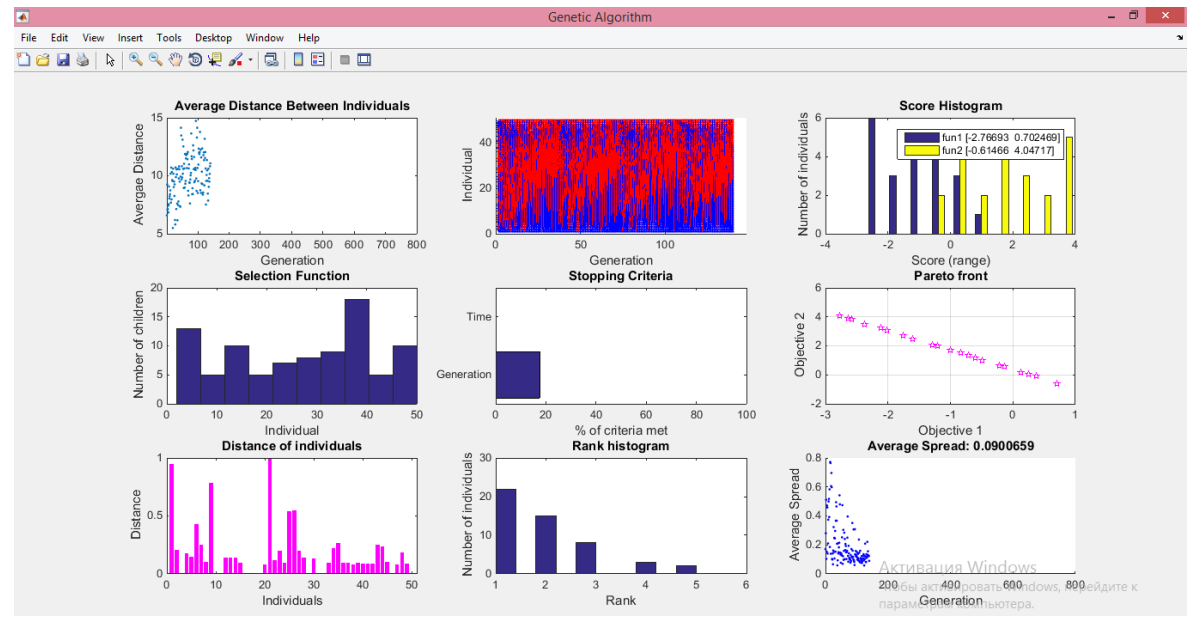

Figure 4. Program results

under study. The M-file with the optimized function with the given restrictions is shown in figure 3 .

To implement a multi-criteria task, use the built-in Optimization ToolBox. The obtained optimization results are shown in figure 4.

\section{Conclusions}

With regard to the optimization of financial stability, this means that we have obtained many key indicators that shape the financial condition of the enterprise and it provides an opportunity to form an effective management strategy aimed primarily at achieving optimal values of indicators that together and determine the economic essence of the financial stability of the enterprise.

The analysis of existing approaches to assessing the financial condition of enterprises shows the lack of a unified methodological basis for this issue. The key problem is the lack of a single indicator that would accumulate all aspects of financial condition. The article proposes a method of assessing and optimizing the financial condition based on the concept of maximizing the financial stability of enterprises Finscore. The formulated problem of multicriteria optimization of indicators CurrentRatio, Equity-to-Assets, NPM and ReceivablesTurnover allows to obtain Paretooptimal combinations, which achieve financial stability as a maximized value (optimal ratio between key indicators of the financial condition of the enterprise).

\section{References}

[1] S. Drobyazko, A. Barwinska-Malajowicz, B. Slusarczyk, O. Chubukova, T. Bielialov, Journal of Risk and Financial Management 13, 300 (2020)

[2] G. Azarenkova, O. Golovko, K. Abrosimova, Accounting and Financial Control 2, 1 (2018)

[3] V. Mokeev, E. Bunova, A. Perevedentceva, Procedia Engineering 129, 681 (2015), international Conference on Industrial Engineering (ICIE-2015)
[4] O. Mykoliuk, V. Bobrovnyk, V. Fostolovych, H. Kucherova, P. Nataliia, Modelling the Level of Energy Security at Enterprises in the Context of Environmentalization of Their Innovative Development, in 2020 10th International Conference on Advanced Computer Information Technologies (ACIT) (2020), pp. 621-625

[5] W. Ma, M. Jin, Y. Liu, X. Xu, Chaos, Solitons \& Fractals 125, 17 (2019)

[6] D.M. Sprčić, A. Kožul, E. Pecina, Zagreb International Review of Economics and Business 20, 25 (2017)

[7] J. Cohen, G. Krishnamoorthy, A. Wright, Contemporary Accounting Research 34, 1178 (2017)

[8] N. Shmygol, O. Galtsova, O. Solovyov, V. Koval, I.W.E. Arsawan, E3S Web Conf. 153, 03001 (2020)

[9] K. Kostetska, N. Khumarova, Y. Umanska, N. Shmygol, V. Koval, Management Systems in Production Engineering 28, 15 (2020)

[10] D. Ocheretin, V. Los, K. Hanna, O. Bilska, E3S Web of Conferences 166, 13024 (2020)

[11] A. Matviychuk, O. Novoseletskyy, S. Vashchaiev, H. Velykoivanenko, I. Zubenko, SHS Web of Conferences 65, 06005 (2019)

[12] I. Khvostina, A. Matviychuk, S. Savina, O. Yatsiuk, Analysis of the Dependence of the Performance of the Ensemble on the Accuracy of its Individual Models, in Proceedings of the 2019 7th International Conference on Modeling, Development and Strategic Management of Economic System (MDSMES 2019) (Atlantis Press, 2019), pp. 371-375, https ://doi . org/10.2991/mdsmes-19.2019.70

[13] V. Soloviev, V. Solovieva, A. Tuliakova, M. Ivanova, Construction of crisis precursors in multiplex networks, in Proceedings of the 2019 7th International Conference on Modeling, Development and Strategic Management of Economic System (MDSMES 2019) (Atlantis Press, 2019), pp. 361-366, https : //doi . org/10.2991/mdsmes-19.2019.68 